\title{
Other-Sex Friendships in Late Adolescence: Risky Associations for Substance Use and Sexual Debut?
}

\author{
Sylvie Mrug • Casey Borch • Antonius H. N. Cillessen
}

Received: 26 August 2010/ Accepted: 3 November 2010/Published online: 19 November 2010

(C) The Author(s) 2010. This article is published with open access at Springerlink.com

\begin{abstract}
Adolescents' friendships with other-sex peers serve important developmental functions, but they may also facilitate engagement in problem behavior. This study examines the unique contributions of other-sex friendships and friends' behavior to alcohol use, smoking, and initiation of sexual intercourse among late adolescent girls and boys. A total of 320 adolescents (53\% girls; 33\% racial/ ethnic minorities) provided sociometric nominations of friendships annually in grades 10-12. Friendship networks were derived using social network analysis in each grade. Adolescents and their friends also reported on their alcohol use, smoking, and sexual debut at each assessment. After controlling for demographics, previous problem behavior, and friends' behavior, other-sex friendships in 10th grade were associated with initiation of smoking among girls over the following year, and other-sex friendships in 11th grade were linked with lower levels of subsequent alcohol use among boys. Additionally, friends' smoking and sexual experience in 10th grade predicted the same behaviors for all adolescents over the following year. Other-sex friendships thus appear to serve as a risk context for adolescent girls' smoking and a protective context for adolescent
\end{abstract}

This research was supported by grant K01DA024700 from the National Institutes of Health to the first author.

\section{S. Mrug $(\square)$}

University of Alabama at Birmingham, 1530 3rd Ave South, 912 bld, Room 133, Birmingham, AL 35294-1200, USA

e-mail: smrug@uab.edu

C. Borch

University of Alabama at Birmingham, 1530 3rd Ave South,

HHB 460C, Birmingham, AL 35294, USA

\author{
A. H. N. Cillessen \\ Radboud University, Nijmegen, The Netherlands
}

boys' drinking. Promoting mixed-gender activities and friendships among older high school students may be helpful in reducing males' alcohol use, but may need to incorporate additional components to prevent increases in females' smoking.

Keywords Peer influence - Other-sex friendships · Alcohol use · Smoking · Sexual debut

\section{Introduction}

Middle and late adolescence is a developmental period in which many youth initiate and/or escalate alcohol use, cigarette smoking, and sexual activity. For instance, national surveys show an increase from 39 to $72 \%$ for lifetime alcohol use, $18-55 \%$ for drunkenness, and $21-45 \%$ for cigarette smoking between ages 14 and 18 (Johnston et al. 2009). Likewise, lifetime rates of sexual intercourse increase from 27 to $66 \%$ and rates of recent (in last 3 months) intercourse increase from 18 to $57 \%$ between 15 and 18 years of age (Centers for Disease Control and Prevention 2008). Thus, this is a key developmental period for the study of risk and protective factors related to the initiation and escalation of health risk behaviors.

One of the strongest risk factors for adolescent substance use and sexual activity is friends' behavior (Ellickson et al. 2008; Henry et al. 2007; Stice et al. 1998; Urberg et al. 1997). Besides friends' behavior, recent studies implicate the sex composition of adolescents' peer networks in the development of some problem behaviors. Specifically, friendships with other-sex peers are related to earlier sexual intercourse (Billari and Mencarini 2003) and higher antisocial activity, especially among girls (Arndorfer and Stormshak 2008; Haynie et al. 2007). However, 
because boys exhibit higher levels of antisocial behavior and earlier initiation of sexual intercourse than girls (Centers for Disease Control and Prevention 2008), it is not clear whether other-sex friends exert negative influences on adolescent girls because of their gender or behavior. To clarify the respective roles of these friends' characteristics, this study examines the prospective contributions of sex composition and behavior of friendship networks to cigarette and alcohol use, as well as sexual debut among adolescent boys and girls.

Other-Sex Friendships and Their Relationship to Problem Behavior

Segregation by sex is a well-characterized feature of friendships that emerges in early childhood (LaFreniere et al. 1984) and is evident throughout the life span (Mehta and Strough 2009) and across different cultures (Maccoby 1998). Although most preadolescent friendships are with same-sex peers, the number of other-sex friendships increases throughout adolescence (Poulin and Pedersen 2007). However, the features of other-sex friendships vary by gender. Adolescent girls report having more other-sex friends than boys, and their other-sex friendships are more likely to occur outside of school and with older peers. These gender differences emerge early in adolescence and increase over time (Poulin and Pedersen 2007). Although youth conceptualize other-sex friendships as clearly distinct from romantic relationships (Connolly et al. 1999), cross-sex friendships have long been considered an important developmental step toward heterosexual dating (Dunphy 1963). In mixed-sex groups, adolescents learn how to relate to the other sex, leading to lower anxiety in social and dating heterosexual situations (LaGreca and Mackey 2007) and greater subsequent engagement in romantic relationships (Connolly et al. 2000). Other-sex friendships thus fulfill several important developmental functions, such as learning to communicate with the other sex and gaining confidence in such interactions, providing emotional support, and facilitating the development of one's gender identity (Sippola 1999).

These positive functions of other-sex friendships notwithstanding, recent literature also links such friendships with negative behaviors, such as earlier sexual intercourse, higher alcohol use, and antisocial activity. Specifically, college students who retrospectively reported having opposite-sex friends in adolescence also reported earlier engagement in sexual intercourse (Billari and Mencarini 2003). The findings were significant for both sexes, but the effects were stronger for males than females. Another study addressing substance use (Dick et al. 2007) found that adolescent twins with other-sex friends were 3 times more likely to report using alcohol than those with only same-sex friends. Finally, several studies examined concurrent or prospective effects of having opposite-sex friends on adolescents' antisocial behavior. Poulin and Pedersen (2007) reported that girls who were more antisocial in 6th grade had more male friends in grades 6 through 10, but there was no relationship between boys' antisocial behavior and other-sex friendships. Similarly, Arndorfer and Stormshak (2008) found that nominating an opposite-sex peer as one of three best friends was associated with concurrent antisocial behavior for girls, but not boys, in 6th grade. Although these concurrent associations did not emerge in 7 th or 8 th grade, nominating an opposite-sex best friend in 6 th and 8th grade predicted subsequent antisocial behavior. Using the large sample of 11-19 year-old adolescents in the Add Health study, Haynie et al. (2007) found that the proportion of other-sex friends (defined as peers who either received or gave a friendship nomination to the target adolescent) at baseline was associated with an increased risk of subsequent violent behavior for girls, but decreased risk of violence for boys. These findings held even after adjusting for adolescents' previous violent behavior, friends' self-reported violence, and demographic covariates. Additional analyses revealed that, for girls, other-sex friendships were linked with higher violence only when the friends reported higher levels of violent behavior. These results indicated that, for girls, friendships with violent boys were associated with increased violence over time, but friendships with non-violent boys were not. For boys, friendships with girls were protective, translating into lower levels of violence regardless of the girls' violent behavior. However, the girls in this study reported very low rates of violence overall, so the results may not generalize to problem behaviors that are more common among females. Altogether, this literature suggests that other-sex friendships are associated with problem behaviors in adolescence and that these relationships may vary by sex.

\section{Alternative Explanations of Other-Sex Friendship Effects}

However, it is not clear whether other-sex friendships actually contribute to problem behavior. Many of the above cited studies used a cross-sectional design (or a prospective design without controlling for adolescents' previous problem behavior), from which the directionality of the relationship between other-sex friendships and problem behavior cannot be determined. For instance, it is possible that adolescents who are more sexually experienced or who use substances are more likely to develop other-sex friendships, or that both problem behaviors and other-sex friendships result from other common causes. Another major limitation of much of this literature is assessing the effects of other-sex friendships without accounting for 
friends' behavior. In particular, because boys tend to have higher rates of many problem behaviors than girls (including violence, substance use, and sexual behaviors; Centers for Disease Control and Prevention 2008), any detrimental effects from opposite-sex friendships for girls may be the result of the boys' greater problem behavior, but not their gender. Thus, a more rigorous investigation of the role of other-sex friendships in the development of problem behavior needs to include a prospective design that controls for adolescents' previous behavior, as well as friends' behavior. When both friends' gender and behavior are considered simultaneously, several hypotheses can be generated about their roles in adolescents' problem behavior. In particular, we focus on substance use and sexual debut, which are the outcome behaviors examined in this study.

\section{Other-Sex Friendships May Lead Directly to Problem Behaviors}

The most straightforward hypothesis is that friendships with other-sex peers are directly responsible for increased substance use and/or initiation of sexual intercourse. Given the consensus in the literature that the primary functions of mixed-sex friendship groups are to provide access to potential romantic partners and to develop interpersonal skills that would facilitate heterosexual romantic relationships (Connolly et al. 2000; Sippola 1999), it appears likely that other-sex friendships may lead directly to dating and in turn to sexual intercourse. Indeed, mixed-sex friendships increase the likelihood of heterosexual dating (Connolly et al. 2000), and dating is a strong risk factor for initiation of sexual intercourse among both adolescent males and females (Miller et al. 1997).

Although the association may be more tenuous, othersex friendships could also lead directly to increased substance use among adolescents. If adolescents viewed the use of alcohol and tobacco as common, desirable and appealing to the other-sex, they may initiate or escalate substance use to impress and be liked by other-sex friends. It is notable that adolescents typically overestimate the prevalence of substance use among their peers (Page et al. 2002). Although little research has addressed substance use norms and expectations for the other sex, a recent study with college students showed that females overestimate the amount of alcohol males want their female friends and partners to drink; importantly, this overestimation contributed to higher levels of drinking among these young women (LaBrie et al. 2009). Similarly, perceived other-sex drinking norms predicted college students' alcohol use beyond same-sex norms (Thombs et al. 2005). Another potential pathway explaining increased substance use among those with opposite-sex friends could be the use of tobacco and alcohol to reduce anxiety associated with heterosexual interactions, such as at mixed-sex parties and gatherings. Thus, other-sex friendships may facilitate sexual debut through increased opportunities for dating, and they may contribute to substance use through biased perceptions of other-sex norms and expectations regarding substance use, as well as through anxiety reduction motives.

\section{Friends' Behavior, but not Sex, May Lead to Problem Behavior}

A second possibility is that friends' behavior is primarily responsible for problem behavior, regardless of the friends' gender. A large literature demonstrates peer influences on both substance use and sexual behavior (e.g. Ellickson et al. 2008; Henry et al. 2007; Stice et al. 1998; Urberg et al. 1997). However, because late adolescent males are more likely to drink alcohol, smoke, and have initiated sexual intercourse than females (Centers for Disease Control and Prevention 2008), girls' friendships with boys may be more likely to facilitate these behaviors due to boys' greater experience with these behaviors.

\section{One Gender May be More Susceptible to Peer Influence}

Another possibility is that girls may be more susceptible to peer influence in general (i.e., from both same-sex and other-sex friends), which may also contribute to findings of stronger negative peer influence from other-sex friendships for girls. Girls' greater susceptibility to peer influence could be explained by their higher quality of friendships (e.g., intimacy, closeness, and caring; see Zarbatany et al. 2000) that generally seems to amplify friends' influence on substance use (Urberg et al. 2003). However, it should be noted that existing findings on sex differences in susceptibility to peer influence are mixed, with some studies not finding sex differences (Fuemmeler et al. 2002; Urberg et al. 2003) and others reporting increased susceptibility for either girls (Dick et al. 2007) or boys (Crosnoe et al. 2002).

\section{The Behavior of Other-Sex Versus Same-Sex Friends May be More Influential}

It is also possible that the behavior of other-sex friends is more influential than the behavior of same-sex friends. In other words, it is not the mere presence of other-sex friends or friends' behavior, but rather the combination of those peers' behavior and opposite-sex status. Behavior of othersex friends might be more influential if these friendships are valued more than same-sex relationships (e.g., they convey higher status in the peer group), making adolescents more willing to adjust their behavior to become more 
similar to their friends in order to maintain these important relationships. Consistent with this hypothesis, friends' alcohol use was more strongly associated with adolescents' own drinking for those reporting having some other-sex friends in the Finnish twin study (Dick et al. 2007).

\section{The Behavior of Other-Sex Versus Same-Sex Friends May be More Influential, but Only for One Gender}

For some outcomes, girls (but not boys) may be more susceptible to the behavior of other-sex friends compared to the behavior of same-sex friends. Girls' greater susceptibility to other-sex friends' behavior has been demonstrated for violence (Haynie et al. 2007). However, given recent evidence suggesting greater propensity of girls to alter their behavior in cross-sex friendships compared with boys (McDougall and Hymel 2007), it may extend to other domains as well. This greater susceptibility to other-sex behavioral influences among girls could be explained by multiple mechanisms, including greater desire for other-sex friendships, better developed interpersonal skills and understanding of the other sex's preferences, or greater willingness or ability to modify own behavior (Rose 2007).

\section{Peer Influences May Vary with Development}

The influence of other-sex friendships may be further modified by developmental factors. Perhaps due to greater maturity and more strongly established self-identity, selfreported resistance to peer influence increases from middle to late adolescence (Steinberg and Monahan 2007). Likewise, self-reported susceptibility to peer influence generally increases in early to middle adolescence and then decreases in late adolescence (Berndt 1979). However, studies that examined developmental differences in the actual effects of peer behavior have not always confirmed these self-report trends. For instance, one study found no differences in peer influences on adolescent smoking between 6th and 11th grade (Chassin et al. 1986). In another investigation, the proportion of friends who smoked had a stronger effect on adolescents' smoking in 11th than in 8th grade, suggesting a stronger, not weaker effect of peer behavior in later adolescence (Urberg et al. 1991). Thus, although some literature suggests that samesex and other-sex friends and friendships may become more influential as adolescents progress through the high school years, other developmental trends may also occur.

In summary, existing literature suggests that other-sex friendships may increase adolescents' problem behavior, but the relative roles of friends' behavior, friends' gender, and adolescents' own gender have not been clarified. Given the scarcity of controlled longitudinal studies, the directionality of the associations is also unclear. Finally, many studies relied on adolescents' self-reports of all variables (own behavior, friends' behavior, and friends' sex) with the possibility that some results are caused or inflated by shared method variance. Therefore, in order to determine whether other-sex friendships truly contribute to adolescents' problem behavior, it is essential to utilize a longitudinal design with multi-informant data, and to account in analyses for previous levels of problem behavior, as well as direct and interactive effects of friends' gender, friends' behavior, and adolescents' gender.

\section{Goals of the Present Study}

This investigation examines the effects of other-sex friendships on adolescents' alcohol and tobacco use and sexual debut in late adolescence. Consistent with existing literature on adolescent peer relationships, we conceptualize friendship influence as present within friendship groups or cliques, defined as cohesive groups of youth who regularly interact with each other (Urberg et al. 1995). To address limitations common in prior research, the current study utilizes multiple informants and a prospective design, and evaluates the unique and interactive contributions of the sex composition of the friendship group, friends' behavior, and adolescents' own sex on changes in substance use and sexual debut over two one-year periods, from 10th to 11th grade and from 11th to 12th grade. Based on the literature reviewed above, we hypothesize that both friends' behavior and opposite-sex friendships will uniquely contribute to the initiation of sexual intercourse, that friends' behavior will be a strong predictor of adolescents' alcohol and tobacco use, that the effects of peer behavior on both substance use and sexual debut will be magnified by the presence of other-sex friends, and that peer influence effects may be stronger when predicting from 10th grade to 11 th grade than from 11th to 12 th grade.

\section{Methods}

Participants and Procedures

Participants were 320 adolescents enrolled in a larger study of social and academic development of youth. The sample included 171 (53\%) girls; 67\% Caucasians, 19\% African Americans, $12 \%$ Hispanics, and 2\% students of other ethnic origin. The study was conducted in a public school district in a mid-sized town in the Northeast of the U.S. The present report includes data collected in three successive years (2002-2004) from a cohort of adolescents attending the same grade in one high school as they progressed from 10th to 12th grade (approximate ages 16-18). The numbers 
of participating students were 363,368 , and 307 out of 543, 528 , and 479 students officially listed in grades 10,11 , and 12 , respectively. Participation rates thus ranged from 64 to $67 \%$ across the 3 years. However, because the analyses used listwise deletion of cases with missing data, participants who did not have complete data for all variables used in a given analysis were excluded from that analysis. The number of cases used in individual analyses thus ranged from 120 to 228. A total of 320 adolescents were used in one or more analyses.

Main reasons for attrition were not being officially listed on the class roster in two consecutive years (e.g., due to moving to another school or dropping out; $11 \%$ from grade 10 to $11,21 \%$ from grade 11 to 12 ); not participating in two consecutive years due to absences, recent move or drop-out, or refusal (20 and 27\%); not providing information about own substance use or sexual behavior (0-2\%); not being a member of a friendship group (6\% in grade 10 ; $36 \%$ in grade 11); and missing information on friends' behavior $(4 \%)$. The analytic sample $(N=320)$ did not differ from excluded cases in gender composition but comprised fewer racial/ethnic minorities. Each data collection was conducted in the spring to ensure sufficient familiarity of students with one another in order to yield valid and reliable sociometric data. Adolescents completed group-administered peer nomination and self-report forms in their classrooms. Identical measures were used at each data collection wave.

\section{Measures}

\section{Alcohol Use}

Adolescents' alcohol use was measured with two selfreport items indicating the frequency of alcohol use ("at least one drink of alcohol") and binge drinking ("5 or more drinks of alcohol in a row") in the last 30 days. Both items were rated on 7-point scales ranging from ' 0 ' to ' 30 days' for drinking and ' 0 ' to '20 or more days' for binge drinking. The two items were averaged within each grade. Combining the frequency of use with the frequency of binge drinking is a commonly used measure of adolescent substance use (e.g., Wills et al. 1998). Using the average was supported by strong correlations between the two items ( $r$ 's $=.74-.81, p<.001$, across grades 10-12), and their nearly identical standard deviations within each wave.

\section{Smoking}

Adolescents' smoking was assessed with one dichotomous item asking adolescents whether they ever tried cigarette smoking.

\section{Sexual Debut}

One dichotomous item assessed adolescent self-report of ever having sexual intercourse.

\section{Proportion of Other-Sex Friends}

As a part of the sociometric nominations, adolescents were asked to nominate their best friends within the entire grade. Students could nominate as many best friends as they liked; both same-sex and other-sex nominations were allowed. Friendship groups were derived using UCINET 6 (Borgatti et al. 2002) and the block modeling techniques therein. The friendship groups were defined as groups of two or more students connected by one or more reciprocal friendship nominations. Dyads are groups in which both students nominated each other as friends. Groups of three include a dyad in which at least one person is reciprocally connected to another person. Groups of four are dyads where both people are reciprocally connected to other students, who may or may not be connected to others in the group. So, each friendship group has at least one dyad and all other connections must adhere to the principle of transitivity. Transitivity refers to the probability that if two people are friends and one of them is friends with a third person, then it is likely that the third person is a part of the larger friendship group. Thus, no student is more than one reciprocal tie from any other student in the friendship group. This method has been used successfully in previous peer relations studies (e.g., Espelage et al. 2003). Friendship groups ranged in size from 2 to 9-11 peers across the three grades. For each adolescent, we then computed the proportion of his or her friends who were of opposite-sex.

\section{Friends' Alcohol Use}

Using the friendship groups described above, we computed the average of the friends' self-reported alcohol use scores described above under "Alcohol use".

\section{Friends' Smoking}

Friends' smoking was computed as the proportion of friends who reported ever smoking, using each friend's self-report of lifetime smoking described above under "Smoking".

\section{Friends' Sexual Initiation}

Friends' sexual initiation was computed as the proportion of friends who reported ever having sexual intercourse using one item described above under "Sexual debut". 


\section{Results}

Descriptive statistics for adolescents and their friendship groups are reported in Table 1; because of hypothesized sex differences, all descriptives are presented separately for males and females. As expected, adolescents' average levels of alcohol use and lifetime prevalence of cigarette smoking and sexual debut generally increased from 10th to 12 th grade, with the exception of somewhat lower rate of cigarette smoking in Grade 11 than in Grade 10. Average clique sizes generally decreased across the 3 years, while the proportion of other-sex clique members increased from 10 th to 11 th grade and then decreased in 12 th grade. In contrast to individual substance use, clique members' average alcohol use and smoking were the highest in Grade 10.

Correlations among all variables are listed in Table 2. The temporal stability of most constructs was low, suggesting substantial developmental changes in individual behavior and the composition of friendship groups over the three-year period. Cross-sectional correlations indicated generally positive significant relationships among the three problem behaviors (alcohol use, smoking, sexual debut) at both the individual and friendship group levels. Interestingly, individual problem behavior was significantly related to friends' problem behavior primarily in Grade 10; in the later grades, only individual and friends' alcohol use were significantly correlated at Grade 11.

The main research questions were addressed with multiple regressions for alcohol use and logistic regressions for the dichotomously coded smoking and sexual debut. Grade 11 outcomes were modeled as a function of variables assessed in Grade 10; Grade 11 variables predicted outcomes in Grade 12. All analyses controlled for racial/ethnic minority status and the level or presence of the same problem behavior in the previous year. Because continuity in behavior was modeled, the analyses evaluated the effects of other predictors on changes in the target behavior over the 1 year period. The main predictors of interest included the proportion of other-sex friends, friends' problem behavior, sex of the adolescent, and all their interactions. The main effects tested whether having other-sex friends, friends' problem behavior, or being male versus female contributed to alcohol use, smoking initiation, or sexual debut over the following year. The 2-way interactions of other-sex friends and friends' problem behavior evaluated the hypothesis that friends' behavior is more influential in the context of mixed-sex friendship groups than in samesex groups. The 2-way interactions between other-sex friends and gender tested whether having opposite-sex friends predicts problem behavior differently for males and females. The 2-way interactions between gender and friends' behavior evaluated the hypothesis that one gender is more susceptible to the influence of friends' behavior (regardless of the friends' sex) than the other. Finally, the 3-way interaction tested the most complex possibility that the behavior of other-sex friends is more influential than behavior of same-sex friends, but only (or more so) for one gender. All predictors were centered prior to computing the interaction terms to reduce problems with collinearity, and significant interactions were followed by simple slope analyses (Aiken and West 1991).

The results are shown in Table 3 for alcohol and Table 4 for smoking and initiation of sexual intercourse. Alcohol use in Grade 11 was marginally predicted by an interaction between other-sex friends and friends' alcohol use; the positive coefficient suggests that friends' alcohol use may more strongly predict higher levels of individual drinking in mixed-sex friendship groups than in same-sex cliques. A different interaction, between other-sex friends and adolescents' sex, emerged in predicting alcohol use in Grade 12. Follow-up simple slopes analyses revealed that the

Table 1 Descriptive statistics for individuals by grade

\begin{tabular}{|c|c|c|c|c|c|c|}
\hline & \multicolumn{2}{|l|}{ Grade 10} & \multicolumn{2}{|l|}{ Grade 11} & \multicolumn{2}{|l|}{ Grade 12} \\
\hline & Males & Females & Males & Females & Males & Females \\
\hline Alcohol use ${ }^{\mathrm{a}}, \mathrm{M}(\mathrm{SD})$ & $.60(1.13)$ & $.47(.93)$ & $60(1.07)$ & $.61(1.01)$ & $.75(1.16)$ & $.71(1.16)$ \\
\hline Ever smoked $(\%)$ & 45 & 47 & 43 & 43 & 50 & 48 \\
\hline Ever had sex (\%) & 26 & 32 & 51 & 50 & 53 & 54 \\
\hline Member of a mixed-sex clique ${ }^{\mathrm{b}}(\%)$ & 31 & 30 & 76 & 65 & 40 & 36 \\
\hline Clique size, $\mathrm{M}(\mathrm{SD})$ & $3.8(1.6)$ & $4.1(1.7)$ & $3.7(1.8)$ & $3.3(1.6)$ & $3.4(1.7)$ & $3.3(1.6)$ \\
\hline Proportion of other-sex friends ${ }^{\mathrm{b}}, \mathrm{M}(\mathrm{SD})$ & $.16(.29)$ & $.12(.21)$ & $.59(.41)$ & $.48(.42)$ & $.20(.29)$ & $.16(.24)$ \\
\hline Friends' alcohol use, M (SD) & $1.40(.94)$ & $1.21(.96)$ & $.71(.82)$ & $.57(.81)$ & $1.15(1.25)$ & $.97(1.07)$ \\
\hline Friends's smoking, M (SD) & $.53(.37)$ & $.51(.37)$ & $.49(.38)$ & $.46(.40)$ & $.40(.35)$ & $.48(.39)$ \\
\hline Friends ever had sex, M (SD) & $.28(.35)$ & $.30(.37)$ & $.37(.33)$ & $.38(.39)$ & $.56(.35)$ & $.44(.39)$ \\
\hline
\end{tabular}

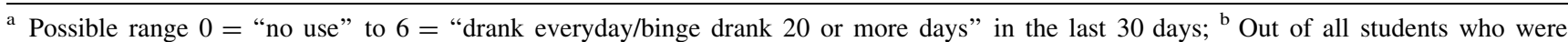
members of a clique 





Table 3 Multiple regression results predicting changes in individual alcohol use from other-sex friendships, friends' alcohol use, and gender

\begin{tabular}{lcc}
\hline Predictor & $\begin{array}{c}\text { Alcohol use } \\
\text { Grade } 11 \\
\beta\end{array}$ & $\begin{array}{c}\text { Alcohol use } \\
\text { Grade } 12 \\
\beta\end{array}$ \\
\hline Alcohol use previous year & .01 & -.09 \\
Racial/ethnic minority & -.04 & .06 \\
Female & .06 & .05 \\
Other-sex friends & .09 & -.07 \\
Friends' alcohol use & -.05 & .02 \\
Other-sex friends $\times$ female & .00 & $.20 *$ \\
Friends' alcohol use $\times$ female & -.03 & .01 \\
Other-sex friends $\times$ friends' & $.15+$ & .06 \\
$\quad$ alcohol use & & .07 \\
Other-sex friends $\times$ friends' & .03 & \\
$\quad$ alcohol use $\times$ female & & $F(9,120)=1.00$ \\
Model $F$ & $F(9,186)=.78$ & .07 \\
Total $R^{2}$ & .04 & \\
\hline All predictors were assessed a &
\end{tabular}

All predictors were assessed a year before the outcome. $+p<.10$; $* p<.05$

proportion of other-sex friends was negatively related to subsequent alcohol use among males $(\beta=-.28, p<.05)$, but unrelated to later alcohol use among females $(\beta=.13$, $p=.31$ ) (see Fig. 1).

Grade 11 smoking was uniquely predicted by a number of Grade 10 variables. The odds ratios presented in Table 4 can be interpreted in the following way: Adolescents who reported smoking in Grade 10 were 4.87 times more likely to report ever smoking the following year, compared with adolescents who did not smoke; racial/ethnic minorities were 3.57 times more likely to initiate smoking between the two assessments compared with Caucasians; youth who had only smoking friends in 10th grade were 4.49 times more likely to start smoking during the following year than peers with no smoking friends; and those who only had other-sex friends (and no same-sex friends) were 6.64 times more likely to start smoking than those with only same-sex friends. However, the last effect was further qualified by an interaction between other-sex friends and adolescent sex. Follow-up analyses indicated that the proportion of other-sex friends positively predicted subsequent smoking for girls, $B=3.41, O R=30.39, p<.01$, but was unrelated to smoking in boys, $B=.37, \quad O R=1.45$, $p=.68$ (see Fig. 1). Girls whose friends were all boys were 30.39 times more likely to start smoking, and girls whose friends were evenly split between boys and girls were 5.50 times more likely to start smoking than girls who did not have any male friends. In contrast to these results, reports of ever smoking the following year (in Grade 12) were not uniquely predicted by any Grade 11 variables.
Likewise, initiation of sexual intercourse between Grades 11 and 12 was not uniquely predicted by any variables measured in the previous year. However, initiation of sexual intercourse between Grades 10 and 11 was predicted by several Grade 10 variables. Racial/ethnic minorities were $69 \%$ less likely to initiate sexual intercourse during that year than Caucasian students, and youth whose friends all reported having had sex in Grade 10 were 2.61 times more likely to initiate sexual intercourse during the year. No effects involving other-sex friends reached significance.

\section{Discussion}

Previous research has shown that the number of other-sex friendships increases in adolescence and that, particularly for girls, these friendships are related to a number of problem behaviors, including substance use, antisocial behavior, and earlier sexual debut (Billari and Mencarini 2003; Dick et al. 2007; Haynie et al. 2007; Poulin and Pedersen 2007). However, existing research has not clarified whether other-sex friendships contribute to changes in problem behavior over time, and whether the effects of other-sex friendships cannot be better explained by greater problem behavior of these friends. This study utilized a prospective design and multiple informants to tease apart the roles of other-sex friendships, friends' behavior, and adolescents' gender in alcohol use, smoking initiation, and sexual debut between 10th and 12th grades in high school.

The main findings revealed that, after controlling for previous levels of adolescents' behavior, sex, and racial/ ethnic minority status, friendships with other-sex peers predicted girls' initiation of smoking between grades 10 and 11, and lower level of boys' alcohol use in grade 12 . Regardless of friends' or the adolescent's own sex, friendships with peers who ever smoked were also associated with the initiation of smoking between grades 10 and 11 , and friendships with peers who had sexual intercourse increased the likelihood of sexual debut between grades 10 and 11. In contrast, friends' recent alcohol use in 10th or 11th grade was not related to a level of recent alcohol use reported by adolescents a year later. As expected, the majority of peer influence effects emerged earlier, from 10 th to 11 th grade, than later, from 11 th to 12 th grade.

The most novel contribution of this study is the demonstration of other-sex friendship influences on problem behaviors. Specifically, 16-17 year-old girls whose friendship groups included a greater proportion of boys were more likely to start smoking, even after adjusting for the friends' lifetime smoking status and other covariates. It is possible that adolescent girls perceive smoking as desirable and appealing to their male friends, and thus are 


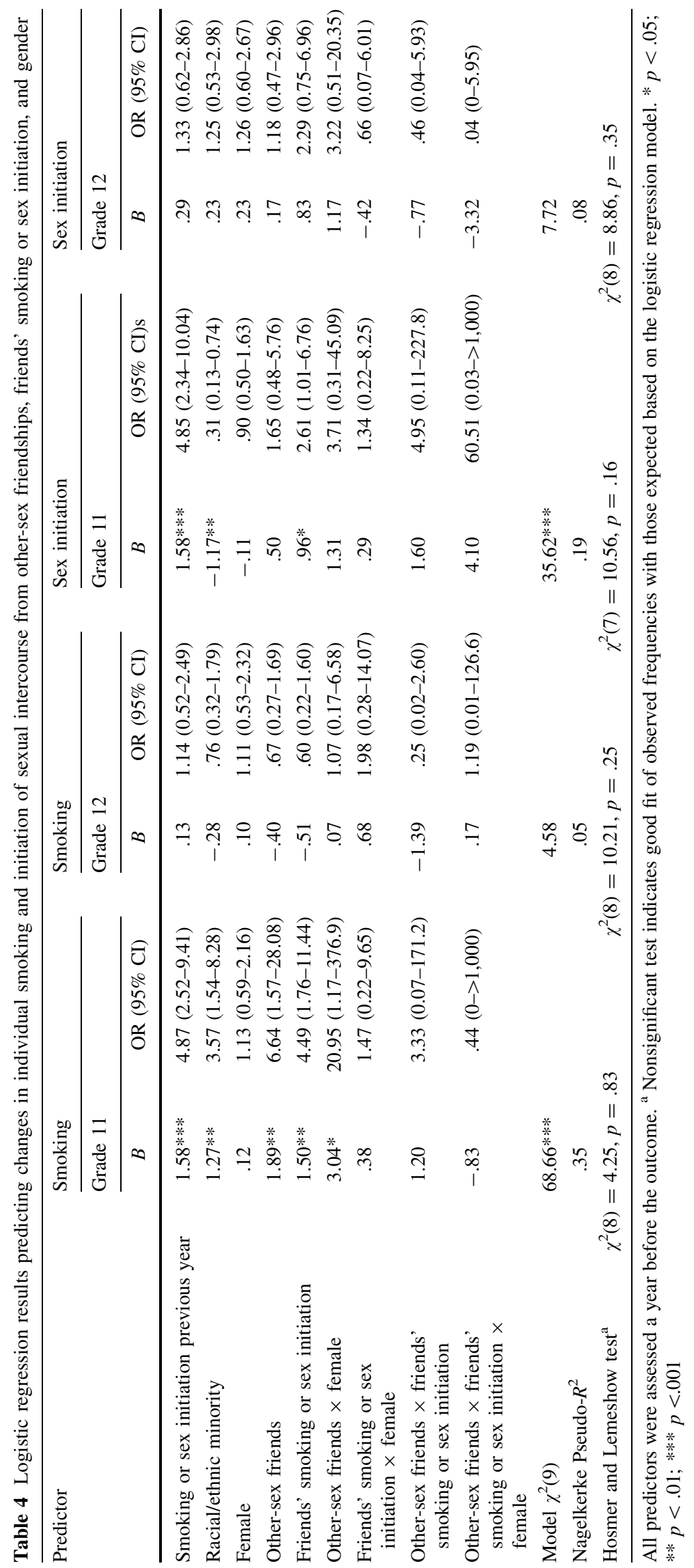





Fig. 1 Other-sex friends as a protective factor for boys' alcohol use and a risk factor for girls' smoking

more likely to initiate smoking to gain their approval. Although no literature has examined this hypothesis directly, multiple studies document the importance of perceived friends' norms for smoking in adolescence (Carvajal et al. 2000; Epstein et al. 2007). A recent study with college students identified perceived approval of smoking by romantic partners as a stronger predictor of smoking than friends' norms (Etcheverry and Agnew 2008), suggesting that perceived approval of smoking by male friends may be especially important to the extent that these friends are viewed as potential romantic partners. Similarly, if girls who are friends with boys are the ones more interested in romantic relationships, these girls may be more likely to start smoking as a way of attracting male partners.

Another possible explanation is that girls whose friendship groups include males are more popular, and thus more receptive to negative socialization influences from the larger peer group. Recent studies indicate that, in line with the popularity-socialization hypothesis, more popular adolescents are more susceptible to acquire behaviors viewed as desirable or normative by the larger peer group, including soft substance use in general (Allen et al. 2005) and smoking in particular (Otten et al. 2009) than less popular peers. There is some evidence suggesting that the negative effect of popularity on smoking may be stronger for adolescent girls than boys (Valente et al. 2005), which may partly explain the association of other-sex friendships with smoking among girls but not boys in the present study.

In contrast with other-sex friendships serving as a risk factor for girls' smoking, such friendships appear to play a protective role in adolescent boys' drinking. Nationally representative studies document consistent gender differences in alcohol use among US late adolescents, with males having both higher prevalence and severity of drinking (Johnston et al. 2009). In studies with college students, females report lower acceptability of drinking than males (Valley 2007), males perceive greater social pressures to drink (Suls and Green 2003), and alcohol use plays a more prominent role in males' than females' social lives (Capraro 2000). It is likely that similar social dynamics operate in the late high school years, with males perceiving more social pressures to drink from their samesex peers and friends. Because adolescent girls drink less and may be less likely to condone or encourage drinking overall, mixed-sex friendship groups likely involve less pressure on males to use and overuse alcohol. The timing of this effect (from 11th to 12th grade, but not a year earlier) may coincide with a time of a normative increase in alcohol use that is especially prominent among males (Johnston et al. 2009; also evident in our descriptive data) and may create a greater opportunity for the protective effect of other-sex friendships.

Surprisingly, other-sex friendships were not related to subsequent initiation of sexual intercourse in either 10th or 11th grade. It is possible that school-based other-sex friendships with same-age peers are not likely to transform into romantic and sexual relationships for most adolescents. Indeed, only $20 \%$ of adolescent girls and $37 \%$ of adolescent boys reported having their first sexual experience with a same-age partner (Manlove et al. 2009). Considering that most adolescents engage in sexual relationships with older or younger partners (Manlove et al. 2009) and at least for girls, many other-sex friendships with boys (especially older boys) occur outside of school (Poulin and Pedersen 2007), it would be important for future studies of sexual initiation to assess the contributions of other-sex friendships that include mixed-age peers from both within school and out of school contexts. Another reason for the lack of prediction of sexual debut between 11th and 12th grade is the small number of adolescents who initiated sexual intercourse during that year $(2 \%)$. 
Thus, this study may have lacked sufficient power to identify predictors of such a small change.

Another hypothesis that was not supported by the present results is that other-sex friendships may amplify the effect of friends' behavior on adolescents' behavior. Our negative results contrast with previous findings by Haynie et al. (2007) that friends' violent behavior was more strongly linked with girls' violence in the context of more other-sex friendships. There are several differences between these two studies that may account for the discrepancy. For instance, different peer dynamics may operate for different types of problem behaviors, and such amplifying effects may occur or be more prominent for violence than substance use or sexual debut. Alternatively, the amplifying effects may occur across multiple behaviors, but may be relatively small in magnitude. Our study would then have insufficient power to detect such effects compared with the sample of over 14,000 in Haynie et al.'s analysis of the Add Health data. Also, these magnifying effects may occur developmentally earlier than the age included in the present investigation (16-19 years), and thus may have appeared only in the mixed-age sample (11-19 years) used by Haynie et al. Finally, our findings may be limited by the exclusion of out-of-school friends. It is possible that older, other-sex friends with whom youth interact in unstructured after-school settings are particularly influential for substance use and sexual behavior.

Our results of friends' smoking and sexual experience predicting the initiation of these behaviors in 16-17 yearold adolescents confirm previous findings with other late adolescent samples (Ellickson et al. 2008; Henry et al. 2007; Urberg et al. 1997). Although the absence of a similar finding for alcohol use at first appears inconsistent with these results and existing literature on peer influences in adolescents' alcohol use (Stice et al. 1998; Urberg et al. 1997), it may be best explained by measurement differences across the three problem behaviors. Because smoking and sexual debut were asked for the adolescent's lifetime, friends' behavior was related to the initiation of these behaviors over the whole 1-year period until the next annual assessment. Alcohol use, on the other hand, was only assessed for the last 30 days. Because friendships and cliques are quite fluid over time (Degirmencioglu et al. 1998), it appears unlikely that friends' drinking at one point in time would be related to the adolescent's drinking 11-12 months later when he or she is likely associating with a different group of peers.

Supporting this explanation, adolescents' own alcohol use was related to current friends' alcohol use $(r=.39$ in Grade $10, r=.28$ in Grade 11, both $p$ 's $<.001$ ), but not to friends' alcohol use a year ago $(r=-.05$ to $-.09, n s)$. Likewise, neither adolescents' own alcohol use nor their friends' alcohol use was stable across the two 1-year periods $(r$ 's $=-.09$ to $.01, n s)$, suggesting substantial changes in individual behavior and/or friendship group composition or behavior over time. Overall, these correlations indicate that late adolescents' recent alcohol use is primarily related to current friends' alcohol use, perhaps as a function of drinking with current friends. However, it is interesting to note that this pattern did not hold in the spring of 12th grade ( $r=.06, n s$, between adolescents' and friends' alcohol use), perhaps as a consequence of adolescents drifting away from school friends as the end of high school approaches. Collectively, these findings suggest that the influence of friendship groups is short-lived, and may be best assessed via more closely spaced assessments (e.g., every 3-6 months), especially if investigating behaviors that show high variability over time.

In terms of developmental differences, our findings generally confirmed the hypothesis that peer influences will be stronger from 10th to 11th grade than from 11th to 12th grade, with the exception of other-sex friendships serving a protective role against males' drinking in 12th grade. One interpretation of these findings is that school-based clique influences on smoking and sexual behavior occur developmentally earlier than such influences on alcohol use, perhaps due to differential timing of substantial increases in each of these behaviors. However, it is important to note that the two sets of analyses were only set 1 year apart, so any developmental differences in the effects of other-sex friendships would be expected to be relatively small.

Some descriptive statistics in this sample were consistent with results of other studies, such as the increasing prevalence of sexual debut and higher alcohol use with age. By contrast, adolescents in this sample reported somewhat lower lifetime prevalence of smoking in 11th grade compared to the previous year. This counterintuitive finding may be best explained by memory bias. Perhaps some adolescents tried smoking prior to the 10th grade assessment, but then did not smoke again and falsely reported never smoking in 11th grade. To avoid such bias, it would be preferable to inquire about smoking using a shorter time frame (e.g., last 12 months or last 30 days), instead of lifetime. In contrast to the generally increasing individual substance use, friends' substance use did not follow the same trend. In particular, friends' substance use was the highest in Grade 10, then decreased, and then increased again. Because the friendship groups were not mutually exclusive and the same adolescents could be included in multiple groups, these trends may reflect the inclusion of substance using adolescents in a greater number of groups in the earlier grades. Alternatively, some of the more heavily using youth may have dropped out of school before the Grade 11 assessments, and thus were included in Grade 10 but not in Grade 11 and 12 friendship groups. The increase in friends' substance use from Grade 11 to Grade 
12 may then reflect a normative increase in alcohol use and smoking, paralleling the same trend in the individual data. Another interesting finding was the increase in other-sex friendships from Grade 10 to Grade 11, followed by a decrease in Grade 12, with both sexes showing a similar trend. Other studies have reported a general increase in other-sex friendships through the grades 6-11, albeit with some gender differences (Connolly et al. 2000; Poulin and Pedersen 2007). However, as neither of these studies included the 12th grade, it is unclear whether the decline in other-sex friendships would replicate in other samples. It is possible that as more students become involved in steadier romantic relationships around Grade 11, the importance and number of other-sex friendships declines in Grade 12.

The present study has a number of strengths that provide important contributions to existing literature on peer influences on adolescents' problem behaviors. It was the first study to examine the unique and interactive contributions of other-sex friendships, friends' behavior, and adolescents' gender on sexual debut and substance use. The prospective design and controlling for previous levels of the outcome allow stronger inferences about the directionality of the peer influences. Importantly, friendship networks derived from sociometric assessments and friends' self-reports were used to measure friends' behavior, thus eliminating the problems of shared-method variance and same-reporter bias present in studies that used adolescents' reports of both their own and their friends' behavior.

On the other hand, the results of the study are limited by the definition of friendships that utilized only same-age, school based peers. As noted earlier, many other-sex friendships, especially for girls, occur outside of school with older peers (Poulin and Pedersen 2007). The present results are thus likely to underestimate the influence of other-sex friendships and friends' behavior, especially for those students whose peer networks include primarily outof-school peers. Some evidence suggests that out-of-school friendship networks are equally or even more influential than school-based friendships, at least for some problem behaviors (Caspi et al. 1993). Thus, it would be important for future research to replicate the present analyses using friendships that occur in multiple social contexts. Of course, studying peer networks outside of school, especially from the perspective of the network members, would be quite challenging, and such studies may need to rely mainly on the adolescents' reports of these friendships and friends' behavior. Ideally, studies on peer influence should try to incorporate both school-based and out-of-school friends and solicit information from the friends' themselves in addition to the target adolescents. Improving on limitations of this study noted earlier, future investigations would also benefit from including more diverse types of problem behaviors, including a broader developmental range (e.g., 13-20 years), and evaluating the hypothesized mechanisms of the effects explicitly.

Another limitation of this study includes differential attrition. The results may not generalize to students who dropped out of high school, moved to a different school, or chose not to participate in the study. These were more likely to be racial/ethnic minorities, so the results may be less generalizable to minority youth. Next, this study investigated other-sex friendships as a predictor of adolescents' behavior. However, other-sex friendships can also be an outcome of adolescents' behavior tendencies, or the two variables may be reciprocally related. Finally, we focused only on one type of risk factor for adolescent problem behavior. Clearly, many other risk and protective factors contribute to adolescent behavior, including family relationships, media, and academic functioning.

Despite these limitations, this study presents novel and interesting findings regarding the role of other-sex friendships in late adolescents' substance use. While friendships with boys represent a risky context that appears to facilitate girls' smoking, friendships with girls seem to protect adolescent boys from excessive drinking. Thus, parents, teachers, and other professionals dealing with older adolescents should be aware that boys with many male friends may be more likely to drink more heavily, while girls with many male friends may be more likely to start smoking. This knowledge can be used to assess current alcohol and cigarette use among these adolescents, and to deliver preventive messages or interventions. Additionally, promoting mixed-gender activities and friendships among older high school students may be helpful in reducing males' alcohol use, but may need to incorporate additional components to prevent increases in females' smoking. Finally, more detailed investigations of the social dynamics underlying these risk and protective effects of other-sex friendships may suggest additional avenues for substance use prevention and intervention programs for youth.

Open Access This article is distributed under the terms of the Creative Commons Attribution Noncommercial License which permits any noncommercial use, distribution, and reproduction in any medium, provided the original author(s) and source are credited.

\section{References}

Aiken, L. S., \& West, S. G. (1991). Multiple regression: Testing and interpreting interactions. London: Sage.

Allen, J. P., Porter, M. R., McFarland, C., Marsh, P., \& McElhaney, K. B. (2005). The two faces of adolescents' success with peers: Adolescent popularity, social adaptation, and deviant behavior. Child Development, 76, 747-760.

Arndorfer, C. L., \& Stormshak, E. A. (2008). Same-sex versus othersex best friendship in early adolescence: Longitudinal predictors 
of antisocial behavior throughout adolescence. Journal of Youth and Adolescence, 37, 1059-1070.

Berndt, T. J. (1979). Developmental changes in conformity to peers and parents. Developmental Psychology, 15, 608-616.

Billari, F. C., \& Mencarini, L. (2003). Gender composition of friendship networks and age at first intercourse: A life-course data analysis. Statistical Methods \& Applications, 12, 377-390.

Borgatti, S. P., Everett, M. G., \& Freeman, L. C. (2002). Ucinet for windows: Software for social network analysis [Computer software]. Harvard, MA: Analytic Technologies.

Capraro, R. L. (2000). Why college men drink: Alcohol, adventure and the paradox of masculinity. Journal of American College Health, 48, 307-315.

Carvajal, S. C., Wiatrek, D. E., Evans, R. I., Knee, C. R., \& Nash, S. G. (2000). Psychological determinants of the onset and escalation of smoking: Cross-sectional and prospective findings in multiethnic middle school samples. Journal of Adolescent Health, 27, 255-265.

Caspi, A., Lyman, D., Moffitt, T. E., \& Silva, P. A. (1993). Unraveling girls' delinquency: Biological, dispositional, and contextual contributions to adolescent misbehavior. Developmental Psychology, 29, 19-30.

Centers for Disease Control and Prevention (2008). Youth risk behavior surveillance-United States, 2007. MMWR, 57 (No. SS-4).

Chassin, L., Presson, C. C., Sherman, S. J., Montello, D., \& McGrew, J. (1986). Changes in peer and parent influence during adolescence: Longitudinal versus cross-sectional perspectives on smoking initiation. Developmental Psychology, 22, 327-334.

Connolly, J. A., Craig, W., Goldberg, A., \& Pepler, D. (1999). Conceptions of cross-sex friendships and romantic relationships in early adolescence. Journal of Youth and Adolescence, 28, 481-494.

Connolly, J. A., Furman, W., \& Konarski, R. (2000). The role of peers in the emergence of heterosexual romantic relationships in adolescence. Child Development, 71, 1395-1408.

Crosnoe, R., Erickson, K. G., \& Dornbusch, S. M. (2002). Protective functions of family relationships and school factors on the deviant behavior of adolescent boys and girls: Reducing the impact of risky friendships. Youth and Society, 33, 515-544.

Degirmencioglu, S. M., Urberg, K. A., Tolson, J. M., \& Richard, P. (1998). Adolescent friendship networks: Continuity and change over the school year. Merrill-Palmer Quarterly, 44, 313-337.

Dick, D. M., Pagan, J. L., Holliday, C., Viken, R., Pulkkinen, L., Kaprio, J., \& Rose, R. J. (2007). Gender differences in friends' influences on adolescent drinking: A genetic epidemiological study. Alcoholism: Clinical and Experimental Research, 31, 2012-2019.

Dunphy, D. C. (1963). The structure of urban adolescent peer groups. Sociometry, 26, 230-246.

Ellickson, P. L., Tucker, J. S., \& Klein, D. J. (2008). Reducing early smokers' risk for future smoking and other problem behavior: Insights from a five-year longitudinal study. Journal of Adolescent Health, 43, 394-400.

Epstein, J. A., Bang, H., \& Botvin, G. J. (2007). Which psychosocial factors moderate or directly affect substance use among innercity adolescents? Addictive Behaviors, 32, 700-713.

Espelage, D., Holt, M., \& Henkel, R. (2003). Examination of peer group contextual effects on bullying during early adolescence. Child Development, 74, 205-220.

Etcheverry, P. E., \& Agnew, C. R. (2008). Romantic partner and friend influences on young adult cigarette smoking: Comparing close others' smoking and injunctive norms over time. Psychology of Addictive Behaviors, 22, 313-325.

Fuemmeler, B. F., Taylor, L. A., Metz, A. E., Jr, \& Brown, R. T. (2002). Risk-taking and smoking tendency among primarily African American school children: Moderating influences of peer susceptibility. Journal of Clinical Psychology in Medical Settings, 9, 323-330.

Haynie, D. L., Steffensmeier, D., \& Bell, K. E. (2007). Gender and serious violence: Untangling the role of friendship sex composition and peer violence. Youth Violence and Juvenile Justice, 5, $235-253$.

Henry, D. B., Schoeny, M. E., Deptula, D. P., \& Slavick, J. T. (2007). Peer selection and socialization effects on adolescent intercourse without a condom and attitudes about the costs of sex. Child Development, 78, 825-838.

Johnston, L. D., O’Malley, P. M., Bachman, J. G., \& Schulenberg, J. E. (2009). Monitoring the future national survey results on drug use, 1975-2008: Volume I, Secondary school students (NIH Publication No. 09-7402). Bethesda, MD: National Institute on Drug Abuse.

LaBrie, J. W., Cail, J., Hummer, J. F., Lac, A., \& Neighbors, C. (2009). What men want: The role of reflective opposite-sex normative preferences in alcohol use among college women. Psychology of Addictive Behaviors, 23, 157-162.

LaFreniere, P., Strayer, F., \& Gauthier, R. (1984). The emergence of same-sex affiliative preferences among preschool peers: A developmental/ethological perspective. Child Development, 55, 1958-1965.

LaGreca, A. M., \& Mackey, E. R. (2007). Adolescents' anxiety in dating situations: The role of other-sex friends, close friends, and romantic partners. Journal of Clinical Child and Adolescent Psychology, 36, 522-533.

Maccoby, E. E. (1998). The two sexes: Growing up apart, coming together. Cambridge, MA: Belknap Press.

Manlove, J., Ikramullah, E., Mincieli, L., Holcombe, E., \& Danish, S. (2009). Trends in sexual experience, contraceptive use, and teenage childbearing: 1992-2002. Journal of Adolescent Health, 44, 413-423.

McDougall, P., \& Hymel, S. (2007). Same-gender versus crossgender friendship conceptions: Similar or different? MerrillPalmer Quarterly, 53, 347-380.

Mehta, C. M., \& Strough, J. (2009). Sex segregation in friendships and normative contexts across the life span. Developmental Review, 29, 201-220.

Miller, B., Norton, M. C., Curtis, T., Hill, E. J., Schvaneveldt, P., \& Young, M. H. (1997). The timing of sexual intercourse among adolescents. Youth \& Society, 29, 54-83.

Otten, R., Wanner, B., Vitaro, F., \& Engels, R. C. M. E. (2009). Disruptiveness, peer experiences, and adolescent smoking: A long-term longitudinal approach. Addiction, 104, 641-650.

Page, R. M., Hammermeister, J., \& Roland, M. (2002). Are high school students accurate or clueless in estimating substance use among peers? Adolescence, 37, 567-574.

Poulin, F., \& Pedersen, S. (2007). Developmental changes in gender composition of friendship networks in adolescent girls and boys. Developmental Psychology, 43, 1484-1495.

Rose, A. J. (2007). Structure, content, and socioemotional correlates of girls' and boys' friendships: Recent advances and future directions. Merrill-Palmer Quarterly, 53, 489-506.

Sippola, L. K. (1999). Getting to know the "other": The characteristics and developmental significance of other-sex relationships in adolescence. Journal of Youth and Adolescence, 28, 407-418.

Steinberg, L., \& Monahan, K. (2007). Age differences in resistance to peer influence. Developmental Psychology, 43, 1531-1543.

Stice, E., Barrera, M., \& Chassin, L. (1998). Prospective differential prediction of adolescent alcohol use and problem use: Examining the mechanisms of effect. Journal of Abnormal Psychology, 107, 616-628.

Suls, J., \& Green, P. J. (2003). Pluralistic ignorance and college student perceptions of gender-specific alcohol norms. Health Psychology, 22, 479-486. 
Thombs, D. L., Ray-Tomasek, J., Osborn, C. J., \& Olds, R. S. (2005). The role of sex-specific normative beliefs in undergraduate alcohol use. American Journal of Health Behavior, 29, 342-351.

Urberg, K. A., Cheng, C. H., \& Shyu, S. J. (1991). Grade changes in peer influence on adolescent cigarette smoking: A comparison of two measures. Addictive Behaviors, 16, 21-28.

Urberg, K. A., Degirmencioglu, S. M., \& Pilgrim, C. (1997). Close friend and group influence on adolescent cigarette smoking and alcohol use. Developmental psychology, 33, 834-844.

Urberg, K. A., Degirmencioglu, S. M., Tolson, J. M., \& HallidayScher, K. (1995). The structure of adolescent peer networks. Developmental Psychology, 31, 540-547.

Urberg, K. A., Luo, Q., Pilgrim, C., \& Degirmencioglu, S. M. (2003). A two-stage model of peer influence in adolescent substance use: Individual and relationship-specific differences in susceptibility to influence. Addictive Behaviors, 28, 1243-1256.

Valente, T. W., Unger, J. B., \& Johnson, C. A. (2005). Do popular students smoke? The association between popularity and smoking among middle school students. Journal of Adolescent Health, 37, 323-329.

Valley, M.A. (2007, May). Injunctive and descriptive social alcohol norms and drinking among college students. Paper presented at the annual meeting of the International Communication Association, San Francisco, CA. Retrieved 12 November 2009, from http://www.allacademic.com/meta/p170343_index.html.

Wills, T. A., Windle, M., \& Cleary, S. D. (1998). Temperament and novelty seeking in adolescent substance use: Convergence of dimensions of temperament with constructs from Cloninger's theory. Journal of Personality and Social Psychology, 74, 387-406.

Zarbatany, L., McDougall, P., \& Hymel, S. (2000). Gender-differentiated experience in the peer culture: Links to intimacy in preadolescence. Social Development, 9, 62-79.

\section{Author Biographies}

Sylvie Mrug is an Associate Professor of Psychology and Health Behavior at the University of Alabama at Birmingham. Her research interests include peer influence and other risk and protective factors for adolescent externalizing behavior.

Casey Borch is an Associate Professor of Sociology at the University of Alabama at Birmingham. His research interests include effects of physical attractiveness on aggression and popularity, adolescent clique formation and maintenance, and the ethnic segregation of adolescent social networks.

Antonius H. N. Cillessen is a professor of developmental psychology in the Behavioural Science Institute and Graduate School at Radboud University, Nijmegen, The Netherlands. His research interests include peer relationships and research methods for developmental psychology. 